Western University

Scholarship@Western

$11-2018$

\title{
Educators' Perceptions of Information Literacy and Skills Required to Spot 'Fake News'
}

Victoria Rubin

University of Western Ontario, Faculty of Information and Media Studies, vrubin@uwo.ca

Nicole Delellis

Western University, ndelelli@uwo.ca

Follow this and additional works at: https://ir.lib.uwo.ca/fimspres

Part of the Library and Information Science Commons

\section{Citation of this paper:}

Rubin, Victoria and Delellis, Nicole, "Educators' Perceptions of Information Literacy and Skills Required to Spot 'Fake News'"' (2018). FIMS Presentations. 54.

https://ir.lib.uwo.ca/fimspres/54 


\title{
Educators' Perceptions of Information Literacy and Skills Required to Spot 'Fake News'
}

\author{
Nicole S. Delellis \\ University of Western Ontario, Canada.ndelelli@uwo.ca
}

\author{
Victoria L. Rubin \\ University of Western Ontario, Canada.vrubin@uwo.ca
}

\begin{abstract}
This research examines the concept of 'fake news' in the context of information literacy (IL) in a post-secondary educational setting. Educators' perceptions shape both IL curricula and classroom discussions with students. We conducted 18 interviews with members of 3 integral groups implementing IL education ( 8 professors, 6 librarians, 4 department chairs). Interviews explored participants' perceptions of: IL education, perceived skills associated with IL, skills required to spot 'fake news', and gaged our participants' willingness to incorporate segments dedicated to detecting 'fake news' in IL curriculum. Our qualitative findings identify a substantial overlap that exists between skills associated with IL and 'fake news' detection (e.g., closereading, critical disposition, bias awareness). Professors and academic administrators also appeared to underappreciate the role of librarians as IL educators. We advocate improving communication among integral facilitators of IL education. More research is needed to assess effectiveness of IL education as an 'inoculation' against 'fake news.'
\end{abstract}

\section{KEYWORDS}

Information Literacy, Perceptions, 'Fake News', Information Literacy Instruction

\section{INTRODUCTION}

What does it mean to be critical of information? In 1989, the American Library Association (ALA) defined information literacy (IL) as a set of skills that enables individuals "to find, evaluate, and use information effectively to solve a particular problem or make a decision." However, as conceptualization of information shifts, and the technologies people use to communicate change, so does the teaching of IL. How we obtain information, and specifically news has been altered by the existence of social media platforms. Blending of traditional news outlets and user generated content procured through social media has influenced how individuals inform themselves (Chen, Conroy and Rubin, 2015). "Most of what we think of as news is now delivered to and received by us in video clips and sound bites, often forwarded without filter or review through social networks from one screen to another in a matter of minutes" (Frederiksen, 2017). Through social media platforms individuals are presented with a decontextualized 'news' sources, often stripped of details about information production. Reliance on social media as a news vector has disrupted traditional methods of information acquisition. Individuals who were once reliant on librarians to provided epistemological protected procured information are now "using the internet to acquire information and making important decisions with it [...] acquiring knowledge from a media where anyone can write anything they want, true or false, anonymously and without consequences" (Walsh, 2010).

Critical assessment of information is important today as it ever has been. Decontextualization of news stories has left individuals who lack IL skills susceptible to 'fake news' deception. Citizens lacking IL skills are predisposed to believing 'problematic information' that is "inaccurate, misleading, inappropriately attributed or altogether fabricated" (Jack, 2017). Researchers have found that "in-spite of the importance of information literacy instruction in higher education, it is still not an integral component of many higher education programs and the students who are going to be graduated from universities are "ill-equipped" with information skills" (Singh, 2011). Past scholars have propagated the idea of IL as a potential cure or remedy that could protect individuals against the disinformation, however few studies have explored IL in relation to 'fake news' in the current state of IL instruction in higher education. It also remains unanswered as to who should take the burden of equipping individuals to be critical evaluators of information.

\section{RESEARCH QUESTION}

Effort has been put into finding technological solutions to the proliferation of misinformation, and disinformation in current online informational spaces (e.g., Rubin (2017), Rubin, Chen, and Conroy (2015)). This research however, focuses on the human side of digital news reading, and how it relates to the broader concept of IL. Revealing educators' perceptions about IL, and 'fake news' is important because these perceptions shape IL curricula, can direct classroom discourse, and form how IL is presented. Specifically, we addressed the following research questions:

1. What perceptions do librarians, professors, and academic administrators have about IL?

2. Should 'fake news' be introduced into IL education?

3. What skills are perceived as necessary to detect 'fake news'? 


\section{METHODS AND ANALYSIS}

This is a case study of a large Southern Ontario Canadian higher educational institution. Perceptions about IL education and 'fake news' were assessed in one-on-one interviews. In winter 2018, we solicited participation of 166 university employees via direct personal e-mail invitations and received a $10.8 \%$ response rate, indicative of a high interest in the topic of the study. Consequently, 18 participants from the invited pool were interviewed face-to-face ( 8 professors, 6 librarians, and 4 department chairs) with an average duration of interviews of 24 minutes (ranging from about 10 minutes to 50 minutes). Interviews contained 11-13 structured question and concluded with an open-ended question. Transcriptions of interviews were analyzed using Glaser and Strauss' (1967) Grounded Theory Approach. A concept map was created to visually display an aggregation of identified concepts that re-appeared as themes in at least 2 of the participants' transcripts (Appendix Figure 1).

\section{MAIN FINDINGS}

In general, all participants emphasized IL as the ability to not only find information, but to evaluate this information synthesized from a variety of sources. Substantial overlap existed in the 18 participants' perceptions of skills associated with IL, and skills thought to be essential for 'fake news' detection. Both skills sets were perceived to contain: an understanding of how language works (close-reading skills), skepticism/critical disposition, an understanding about how information is produced, an awareness of biases (both internal and external), and the ability to synthesize various sources/perspectives. Perceived overlap in skill sets (Figure 1) emphasizes the inherent connection between IL and 'fake news' detection, and provides insights into why participants perceived that skills required to detect 'fake news' are an extension to general IL skills.

Almost all interviewees (17 out of 18) believed that it is important for students to be information literate upon graduation, and more than half (10 out of 18) agreed that segments about 'fake news' should be included in IL curriculum. Participants perceived IL to be an essential citizens' education, which enables individuals to be able to function and engage in democratic societies. As of early 2018, our participants report that only limited curricula include segments dedicated specifically to 'fake news'. Also, librarians are underutilized in the IL education within our case study sample. Researchers in Library and Information Science have proclaimed that "the role of librarians and information professional is to develop well-educated information consumers" (El Rayess et al., 2018), but neither set of interviewed professors or department chairs mentioned librarians when asked who should be teaching IL.

\section{CONCLUSION}

Based on interviews with 18 participants within our case study's post-secondary Canadian institution, we noticed a substantial overlap in recurring concepts associated with their perceptions of IL skills, and skills required to spot 'fake news' (see Appendix Figure 1). Participants saw IL skills being applied towards the broader societal concern of producing critically thinking, aware, information literate citizens. We also identified an unfortunate disconnect between the awareness of the value of IL education, and its universal implementation across the institution. Further research needs to assess the effectiveness of current IL education in imparting perceived skills of critical evaluation of information. In the time being, we recommended for institutions to more proactively facilitate open communication between professors, librarians, and academic administrators to enable the building of curricula, and concrete detailed plans to provide IL education to every student, across every discipline.

\section{REFERENCES}

American Library Association (1989), Presidential Committee on Information Literacy: Final Report, American Library Association, Washington, DC, Retrieved from http://www.ala.org/acrl/publications/whitepapers/presidential

Chen, Y., Conroy, N.J., \& Rubin, V.L. (2015). News in an online world: the need for an automatic crap detector. Proceedings of the $78^{\text {th }}$ ASIS\&T Annual Meeting: Information Science with Impact: Research in and for the Community. American Society for Information Science, 81.

El Rayess, M., Chebl, C., Mhanna, J., \& Hage, R. (2018). Fake news judgement. Reference Services Review, 46(1), 146-149.

Frederiksen, L. (2017). Best of the Literature: Fake News. Public Services Quarterly, 13, 103-107.

Jack, C. (2017). Lexicon of lies: terms for problematic information. Data \& Society. Retrieved from https://datasociety.net/pubs/oh/DataAndSociety_LexiconofLies.pdf

Rubin, V. L., Chen, Y. \& Conroy, N. J. (2015). Deception Detection for News: Three Types of Fakes. Proceedings of the $78^{\text {th }}$ ASIS\&T Annual Meeting: Information Science with Impact: Vol. 81.

Rubin, V. L. (2017). News Verification Suite: Towards System Design to Supplement Reporters' and Editors' Judgements. Proceedings of the $45^{\text {th }}$ Annual Conference of the Canadian Assoication for Information Science L'Association canadienne des sciences de l'information (CAIS/ACSI2017), Toronto.

Walsh, J. (2010). Librarians and controlling disinformation: Is multi-literacy instruction the answer? Library Review, 59(7), 498-511. 

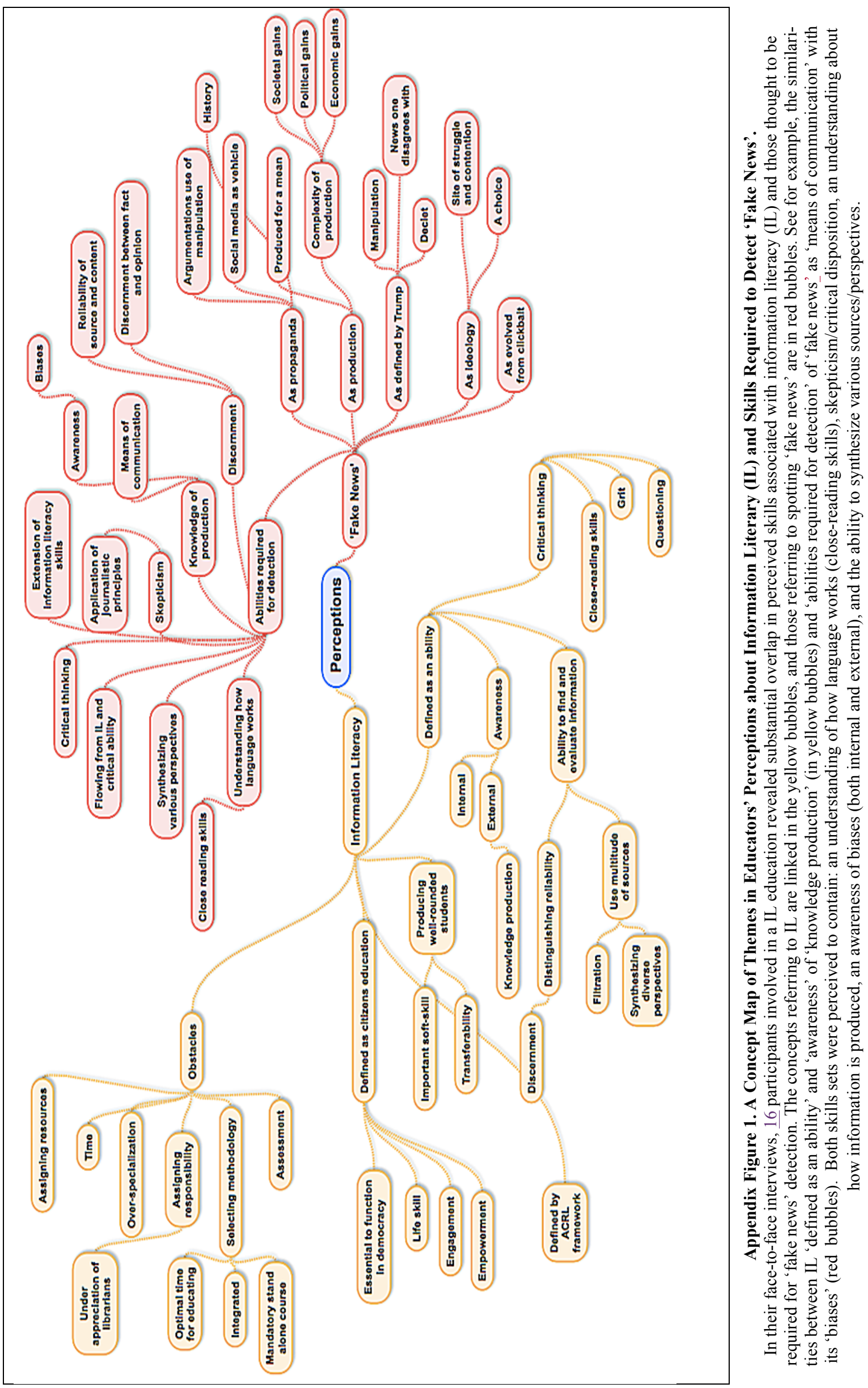